\title{
EARLY LIFE EXPOSURE TO GENISTEIN AND DAIDZEIN DISRUPTS STRUCTURAL DEVELOPMENT OF REPRODUCTIVE ORGANS IN FEMALE MICE
}

\section{Jovana Kaludjerovic, Jianmin Chen, Wendy E. Ward \\ QUERY SHEET}

This page lists questions we have about your paper. The numbers displayed at left can be found in the text of the paper for reference. In addition, please review your paper as a whole for correctness.

Q1: $\quad$ Au: For Bern pls specify pages.

Q2: $\quad$ Au: For Kaludjerovic et al. 2011, pls update with volume and page numbers, or else give doi of epub.

\section{TABLE OF CONTENTS LISTING}

The table of contents for the journal will list your paper exactly as it appears below:

Early Life Exposure to Genistein and Daidzein Disrupts Structural Development of Reproductive Organs in Female Mice Jovana Kaludjerovic, Jianmin Chen, and Wendy E. Ward 
Journal of Toxicology and Environmental Health, Part A, 75:1-12, 2012

Copyright $\odot$ Taylor \& Francis Group, LLC

ISSN: $1528-7394$ print / 1087-2620 online

DOI: $10.1080 / 15287394.2012 .688482$

\title{
EARLY LIFE EXPOSURE TO GENISTEIN AND DAIDZEIN DISRUPTS STRUCTURAL DEVELOPMENT OF REPRODUCTIVE ORGANS IN FEMALE MICE
}

\author{
Jovana Kaludjerovic ${ }^{1}$, Jianmin Chen ${ }^{1}$, Wendy E. Ward ${ }^{1,2}$ \\ ${ }^{1}$ Department of Nutritional Sciences, Faculty of Medicine, University of Toronto, Toronto, \\ Ontario, Canada \\ ${ }^{2}$ Department of Kinesiology, Center for Bone and Muscle Health, Faculty of Applied Health \\ Sciences, Brock University, St. Catharines, Ontario, Canada
}

In mice, exposure to isoflavones (ISO), abundant in soy infant formula, during the first $\mathbf{5} \mathbf{d}$ of life alters structural and functional development of reproductive organs. Effects of longer exposures are unknown. The study objective was to evaluate whether exposure to a combination of daidzein and genistein in the first 10 compared to $5 \mathrm{~d}$ of life results in greater adverse effects on ovarian and uterine structure in adult mice. Thirteen litters of 8-12 pups were cross-fostered and randomized to corn oil or ISO $(2 \mathrm{mg}$ daidzein $+5 \mathrm{mg}$ genistein $/ \mathrm{kg}$ body weight/d) for the first 5 or $10 \mathrm{~d}$ of life. The 10-d protocol mimicked the period when infants are fed soy protein formula (SPF) but avoids the time when suckling pups can consume the mother's diet. Body and organ weights_and histology of ovaries and uteri were analyzed. There were no differences in the ovary or uterus weight, number of ovarian follicles, number of multiple oocyte follicles, or percent of ovarian cysts with 5 or $10 \mathrm{~d}$ of ISO intervention co $\equiv$ red to respective controls. The 10-d ISO group had higher body weights from $6 \mathrm{~d}$ to $4 \mathrm{mo}$ of age and a higher percent of hyperplasia in the oviduct than the respective control. Lower numbers of ovarian corpus lutea and a higher incidence of abnormal changes were reported in the uteri of both ISO groups compared to their respective cepls. Five-and 10-d exposure to ISO had similar long-lasting adverse effects on the structure $\overline{\bar{v}}$ ovaries and uterus in adult mice. Only the 10-d ISO exposure resulted in greater body weight gain at adulthood.

言


organisms at concentrations that are far below the levels deemed harmful in adults (Bern 1992; Newbold et al. 2006). Consequently, questions have been raised regarding the safety of ISO and the potential chronic adverse health effects among adults who were exposed to SPF during infancy (Dinsdale and Ward 2010), and therefore long-term prospective trials evaluating safety are ongoing (Gilchrist et al. 2004).

The sole retrospective cohort study of young adults found no differences in pubertal maturation, growth, or a wide range of reproductive measures between those who were fed SPF and those who were fed cow's milk formula during infancy (Strom et al. 2001). The only reported difference was that women fed SPF had on average an 8-h longer duration of menstrual bleeding and greater discomfort during menstruation compared to women fed cow's milk formula. No clinical studies evaluated the potential effects of SPF on ovarian follicle development, but few studies examined the development of reproductive organs of infants fed SPF in the first few months or years of life (Bernbaum et al. 2008; Gilchrist et al. 2010; Zung et al. 2008). One study reported no marked difference in reproductive organ size, as measured by ultrasound, between infants fed SPF, breast milk, or cow's milk formula at 4 mo of age (Gilchrist et al. 2010). In contrast, prospective studies of healthy infant fed breast milk, cow's milk or SPF showed that females fed SPF display, enhanced vaginal wall cell maturation at 6 mo of age (Bernbaum et al. 2008) and more developed breast tissue at $2 \mathrm{yr}$ of age than infants fed breast milk or cow's milk formula (Zung et al. 2008). Thus, despite its long history of use there is some concern that exposure to ISO present in SPF may exadverse effects on developing infants. In 2010, the U.S. National Toxicology Program Center for the Evaluation of Risks to Human Health Reproduction (NTPCERHR) concluded there was minimal concern (level 2) that SPF, containing ISO, produced, adverse reproductive and/or developmental effects in exposed humans, but acknowledged the paucity of well-designed clinical studies to fully address concerns (McCarver et al. 2011). In contrast, the European Society for
Paediatric Gastroenterology Hepatology and Nutrition (ESPGHAN) has taken a more cautious approach and is advising the public to avoid the use of SPF, especially for infants less than 6 mo of age, because of uncertainties regarding safety in infants and young children (Agostoni et al. 2006).

The CD-1 mouse model, a common animal model for studying environmental estrogens, is useful to predict effects in humans and explore their mechanism of action (Jefferson et al. 2002; 2005; 2006a; 2006b; 2007a; 2007b; 2009; Tewbold et al. 2001). To date, studies reported that short-term exposure (i.e., first $5 \mathrm{~d}$ of life) to genistein irreversibly disrupts development by increasing the risk of obesity, metabolic dysfunction, tumors including tterine fibroids, ovarian and mammary gland eancer, and reproductive problems including infertility/subfertility, endometriosis, and mut tiple oөcyte follicles (MOF) several weeks or months posttreatment_(Dinsdale et al. 2011; Jefferson et al. 2002; 2005; 2006; 2009; Newbold et al. 2001). A recent study showed that F1 females exposed to ISO for the first 10 or $21 \mathrm{~d}_{\alpha}$ of life have reduced fertility by 55 and $60 \%$, respectively F2 females is not compromised (Dinsdale et al. 2011). In contrast, exposure to daidzein and genistein during the first $5 \mathrm{~d}$ of life promotes bone development and attenuate deterioration of bone tissue during aging by stimulating bone calcification and bone matrix formation (Kaludjerovic and Ward 2008; 2009; 2010; Migliaceio 1996; Piekarz and Ward 2007). Because timing of ISO exposure may modulate metabolic regulation and, in turn, the risk of adult-onset diseases, it is important to investigate how duration of exposure during early life influences structural development of reproductive organs, timing of puberty, sexual behaviour, and fertility of sexually mature animals. The objective of this study was to determine how 5 versus $10 \mathrm{~d}$ of exposure to a combination of daidzein and genisteinthe most abundant ISO present in SPFmodulates weight and structural development of ovaries and uterus of female CD-1 mice at adulthood.

\section{5}

Please move Migliaccio 19 reference fror 136 to line 11 


\section{METHODS}

\section{Animals and Treatment}

Six-week-old CD-1 mice ( $n=5$ males, $n=13$ females) obtained from Charles River

Laboratories Canada (St. Constant, QC) were housed in the Department of Comparative Medicine at the University of Toronto. Mice were housed at $23^{\circ} \mathrm{C}$ and $50 \%$ humidity on a 12:12-h light-dark cycle, fed a semipurified diet (AIN93G) devoid of estrogenic compounds, and provided water ad libitum. After 2 wk of adaptation to the environment, mice were mated harem style. Thirteen litters with 8-12 pups were cross-fostered and randomized to corn oil or ISO (2 $\mathrm{mg}$ daidzein $/ \mathrm{kg}$ body weight $/ \mathrm{d}+5 \mathrm{mg}$ genistein $/ \mathrm{kg}$ body weight/d) for the first 5 or $10 \mathrm{~d}$ of life. The 5-d protocol was selected to mimic previously published studies investigating environmental and dietary estrogens (Jefferson et al. 2002; 2005; 2006b; 2007a; 2009; Newbold et al. 2001), and the 10-d protocol was chosen to more closely represent the period in which human infants fed SPF may be exposed to ISO but avoiding the time when suckling pups may start to consume mother's diet. Purified daidzein and genistein powder, purchased from Sigma-Aldrich (Mississauga, ON), was solubilized in $1 \mathrm{ml}$ dimethyl sulfoxide (DMSO) and suspended in corn oil (Kaludjerovic and Ward 2009). Each morning, treatments were administered via subcutaneous injection using a total volume of $20 \mu \mathrm{l} / \mathrm{pup} / \mathrm{d}$. Kaludjerovic et al. (2011) previously showed that subcutaneous (sc) delivery versus oral feeding, and daily versus multiple oral doses, do not result in significantly different levels of total serum daidzein, genistein, equol and O-DMA in the developing CD-1 mice. However, oral feeding in the first week of life is difficult because of the pup small body size. Oral feeding also results in higher variability of serum ISO concentrations, marked stress and a higher risk of death due to aspiration or perforation of tissues than administering somes by injection (Kaludjerovic et al. 2011). The administered dose results in serum ISO levels that are similar to those of human infants fed SPF
(Kaludjerovic and Ward 2009; Kaludjerovic et al. 2011). On postnatal day (PND) 21, 200 mice were weaned, and thereafter only female mice were studied because our previous findings showed that female mice have a greater response to ISO exposure (Kaludjerovic and Ward 2009; 2010). Body weight of mice was measured daily from birth to PND 10, at weaning (PND 21), and every $4 \mathrm{wk}$ thereafter until PND 120, representing young adulthood (Ward et al. 2007). Necropsy occurred at 4 mo of age, at which time organs were collected and stage of estrous cycle was not established. Organ weight was used to monitor for gross adverse effects due to ISO. All procedures involving live animals were reviewed and approved by the University of Toronto Animal Care Committee and compliant with the Canadian Council on Animal Care (Canadian Council on Animal Care 1993).

\section{Histology}

Ovaries and uteri were excised and fixed in $10 \%$ buffered formalin. Samples were embedded in paraffin and sectioned using the method developed by Jefferson et al. (2009) and Newbold et al. (2009) such that 18 sections per mouse were analyzed with a maximum interval of $450 \mu \mathrm{m}$. Tissue sections were stained with hematoxylin and eosin (H\&E) and evaluated by light microscopy. Both uterine horns were cut $1 \mathrm{~mm}$ from the uterine body. The cervix (10-d treatment only) was obtained from the caudal portion of uterine body. Six serial sections (each at an interval of $100 \mu \mathrm{m}$ ) were evaluated for each mouse. The ovary, oviduct, uterus, and cervix were analyzed by a blinded observer (J. C.) to determine the presence of abnormalities. Secondary follicle is defined as pre-antral follicle that represents theca cells, multiple layers of granulosa cells, and the zona pellucid, while tertiary follicle is defined as antral follicle that contains antrum (fluid-filled cavity) (Amleh and Dean 2002; Arango and Donahoe 2008).

\section{Statistics}

The numbers of follicles (secondary to tertiary follicles) and corpus lutea (CL) per mouse 
are presented as mean \pm standard error of mean. All other data are presented as a proportion of mice within the group having the abnormality. Student's $t$-test was used to compare litter size, body weight, and uterine and erarian as well as the number of follicles between the control and ISO treatment group for the 5- and 10-d interventions, respectively. All other frequencies were evaluated by chi-squared (Fisher exact) test. All analyses were performed using Sigma Stat. Statistically significant differences were defined as $p<.05$.

\section{RESULTS}

\section{Litter Size, Body Weight, and Relative Organ Weight}

There were no differences in litter size and birth weight among the respective control and ISO groups (data not shown). Body weight from birth to 4 mo of age was not significantly different between the 5-d ISO group and its respective control (Figure 1). In contrast, 10-d treated females had significantly higher body weight from PND 6 to 4 mo of age compared to its respective control group (Figure 1 ). The 5- or 10-d ISO exposure had no effect on the weight of ovaries, uteri, kidneys, and liver when

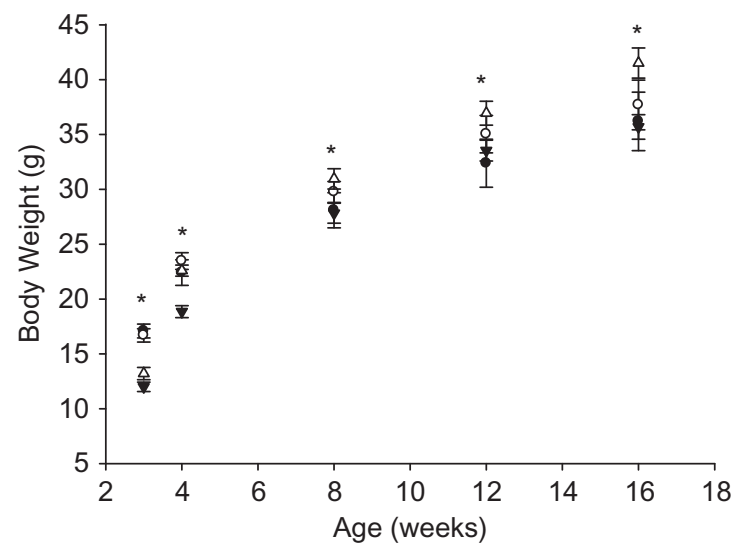

FIGURE 1. Body weight from weaning to 4 mo. of age of mice treated for the first 5 or $10 \mathrm{~d}$ of life with corn oil or ISO: o denotes $5 \mathrm{~d}$ corn ISO group; $\bullet$ denotes $5 \mathrm{~d}$ corn oil group; $\Delta$ denotes $10 \mathrm{~d}$ ISO group; $\boldsymbol{\Delta}$ denotes $10 \mathrm{~d}$ corn oil group; asterisk indicates significant difference, $10-\mathrm{d}$ ISO group $>10-\mathrm{d}$ corn oil group, $p<.05$. expressed as percent body weight (Table 1). Absolute liver weight of 5- and 10-d treated ISO groups was significantly higher than that of its respective control group, with no differences in absolute weight of other organs with either 5 or $10 \mathrm{~d}$ ef ISO exposure (Table 1).

\section{Ovary and Oviduct}

There was no significant difference in the number of follicles, from secondary to preovulatory follicles, between the respective control and ISO groups (Table 2). The number of $\mathrm{CL}$ was significantly lower in the ISO groups compared to their respective controls, of which 5 mice in the 5-d ISO (41.7\%) and one mouse in the $10-d$ ISO $(7.7 \%)$ groups had no $\mathrm{CL}$ (Table 2; Figure 2A). Ovaries without CL were filled with interstitial cells in the stroma (Figure 2A). Three mice from the 5-d ISO $(25.0 \%)$ and one from the $10-d$ ISO $(7.7 \%)$ group showed abnormal cyst-like structure in the ovaries (Figure 2B). One mouse from each 10-d group, CON and ISO, had one MOF (Table 2; Figure 2€). ISO treatment induced hyperplasia, with mucosal folds extending to serosa, in the oviduct of 3 out of $12(25.0 \%)$ and 5 out of $13(38.5 \%)$ mice in the 5 - and $10-d$ ISO groups, respectively (Table 2; Figure $2 \mathrm{~B}_{\mathrm{L}}$.

\section{Uterus and Cervix}

A significantly higher frequency of abnormal changes was observed in the ISO groups, 7 out of $12(58.3 \%)$ and 8 out of $13(69.2 \%)$ in the 5- and 10-d ISO groups, respectively (Table 2). There were two types of alterations observed in the uterus: endometrial hyperplasia and edema in the stroma. Hyperplasia was the major histological change in the mice treated with ISO and only one mouse in the 10-d control group had hyperplasia (Table 2). Hyperplasia with endometrial gland complex, consisting of multiple glands or glandular crowding with glands interconnecting (Figure $3 \mathrm{~A}_{\mathbf{\lambda}}$ and $3 \mathrm{~B}$, was observed only in the ISO-treated mice. Moreover, 3 out of $12(25.0 \%)$ and 2 out of $13(14.4 \%)$ mice from the 5- and 10-d ISO 
IABLE 1. Organ Weights From 4 me-Old Female-Aice Expressed Both as Percent of Body Weight and as Abselute

\begin{tabular}{|c|c|c|c|c|}
\hline & $5 d C O N$ & $5 \mathrm{~d}+\mathrm{s} \theta$ & $10 \mathrm{dCON}$ & 10 dise \\
\hline \multicolumn{5}{|c|}{ Organ weight expressed as percent of body weight } \\
\hline Ovaries & $\theta .0513 \pm 0.0036$ & $\theta .0543 \pm 0.0038$ & $\theta .0589 \pm 0.00396$ & $0.117 \pm 0.0335$ \\
\hline Uterus & $0.3966 \pm 0.0527$ & $0.4373 \pm 0.0503$ & $\theta .413 \pm 0.0382$ & $\theta .357 \pm 0.0449$ \\
\hline Kidney & $1.055 \pm 0.0412$ & $1.028 \pm 0.0439$ & $1.148 \pm 0.125$ & $1.109 \pm 0.0703$ \\
\hline Hiver & $4.080 \pm 0.113$ & $3.759 \pm 0.134$ & $4.425 \pm 0.206$ & $4.636 \pm 0.153$ \\
\hline \multicolumn{5}{|c|}{ Abselute organ weight } \\
\hline Ovaries & $\theta .0191 \pm 0.0016$ & $\theta .0206 \pm 0.0016$ & $\theta .0220 \pm 0.00131$ & $\theta .0485 \pm 0.0143$ \\
\hline Uterus & $\theta .139 \pm 0.014 \theta$ & $0.163 \pm 0.0187$ & $0.153 \pm 0.0119$ & $0.151 \pm 0.0187$ \\
\hline Kidney & $\theta .390 \pm 0.0208$ & $0.387 \pm 0.0167$ & $\theta .430 \pm 0.0442$ & $\theta .454 \pm 0.027 \theta$ \\
\hline Liver & $1.56 \pm 0.139$ & $1.45 \pm 0.0947$ & $1.729 \pm \theta .154^{b}$ & $1.947 \pm 0.107 \mathrm{a}$ \\
\hline
\end{tabular}

Note. Bata are presented as mean \pm standard error of mean. Different superseripts in a row denote significant differences among groups, $p \leq .05$.

TABLE 2. Histological Abnormalities of Ovaries, Oviducts, Uteri, and Cervix of CD-1 mice at 4 mo of Age

\begin{tabular}{|c|c|c|c|c|}
\hline & $5 \mathrm{~d} C O N$ & $5 \mathrm{~d}$ ISO & $10 \mathrm{~d}$ CON & $10 \mathrm{~d}$ ISO \\
\hline \multicolumn{5}{|l|}{ Ovary } \\
\hline Follicles, n/ovary & $9.9 \pm 1.1$ & $10 \pm 1.1$ & $13 \pm 1.4$ & $11 \pm 1.3$ \\
\hline Corpus luteum (CL), n/ovary & $9.1 \pm 1.2^{\mathrm{a}}$ & $4.3 \pm 1.7^{b}$ & $11 \pm 1.3^{\mathrm{a}}$ & $5.1 \pm 0.68^{b}$ \\
\hline Absence of $\mathrm{CL}, n / n$ total $(\%)$ & $0 / 11(0)^{\mathrm{a}}$ & $5 / 12(41.7)^{b}$ & $0 / 12(0)$ & $1 / 13(8)$ \\
\hline Cysts, $n / n$ total $(\%)$ & $0 / 11(0)$ & $3 / 12(25.0)$ & $0 / 12(0)$ & $1 / 13(8)$ \\
\hline MOF, $n / n$ total $(\%)$ & $0 / 11(0)$ & $0 / 12(0)$ & $1 / 12(8)$ & $1 / 13(8)$ \\
\hline \multicolumn{5}{|l|}{ Oviduct } \\
\hline Hyperplasia, $n / n$ total (\%) & $0 / 11(0)$ & $3 / 12(25)$ & $0 / 12(0)^{\mathrm{a}}$ & $5 / 13(39)^{b}$ \\
\hline \multicolumn{5}{|l|}{ Uterus } \\
\hline Abnormal, $n / n$ total $(\%)$ & $0 / 11(0)^{\mathrm{a}}$ & $7 / 12(58)^{b}$ & $1 / 12(8)^{\mathrm{a}}$ & $8 / 13(69)^{b}$ \\
\hline Hyperplasia, $n / n$ total (\%) & $0 / 11(0)^{\mathrm{a}}$ & $6 / 12(50)^{b}$ & $1 / 12(8)$ & $5 / 13(39)$ \\
\hline Atypia, $n / n$ total $(\%)$ & $0 / 11(0)$ & $3 / 12(25)$ & $0 / 12(0)$ & $2 / 13(15)$ \\
\hline Polyps, $n / n$ total $(\%)$ & $0 / 11(0)$ & 1/12 (8) & $0 / 12(0)$ & $1 / 13(8)$ \\
\hline Cyst, $n / n$ total $(\%)$ & $0 / 11(0)$ & $2 / 12(17)$ & $0 / 12(0)$ & $1 / 13(8)$ \\
\hline Edema, $n / n$ total (\%) & $0 / 11(0)$ & $1 / 12(8)$ & $0 / 12(0)$ & $4 / 13(31)$ \\
\hline \multicolumn{5}{|l|}{ Cervix } \\
\hline Microglandular structures, $n / n$ total (\%) & Not tested & Not tested & $0 / 12(0)$ & $4 / 13(31)$ \\
\hline
\end{tabular}

Note. Data are presented as mean \pm standard error of mean or the proportion of mice within the group having abnormality. Different superscripts in a row denote significant differences among groups, $p \leq .05$. Numbers in parentheses represent the percent of mice, out of the total number of mice studied, for which the effect was observed. Abbreviations: control, CON; corpus luteum, CL; multiple oocyte follicle, MOF; soy isoflavones, ISO.

groups, respectively, showed hyperplasia with atypia. One mouse from each ISO group developed endometrial polyps, abnormal projections of endometrium into lumen $(8.3 \%$ and $7.7 \%$, for 5 - and $10-d$ groups, respectively) (Figure 3A). In addition, cystic hyperplasia was also presented in the ISO groups with 2 out of $12(16.7 \%)$ and 1 out of $13(7.7 \%)$ for
5- and 10-d ISO groups, respectively (Table 2; Figure $3 \mathrm{~B}$ ). Endometrial edema existed in the ISO groups with 1 out of 12 (8.3\%) and 4 out of $13(30.8 \%)$ for 5 - and 10-d ISO groups, respectively (Table 2; Figure $3 €$ ). In the cervix, the microglandular structures in the epithelium were observed in mice treated with $10 \mathrm{~d}$ of exposure to ISO at incidence 4 out of 13 $(30.8 \%)$ (Table 2; Figure 3日).

\section{DISCUSSION}

This is the first study to show that 5 and 335 $10 \mathrm{~d}$ of exposure to ISO exerted similar adverse effects on structural development of ovaries and uteri in sexually mature female mice. Both 5 and $10 \mathrm{~d}$ of ISO exposure resulted in a lower number of ovarian $\mathrm{CL}$ and a higher incidence of oviduct hyperplasia, as well as a higher 

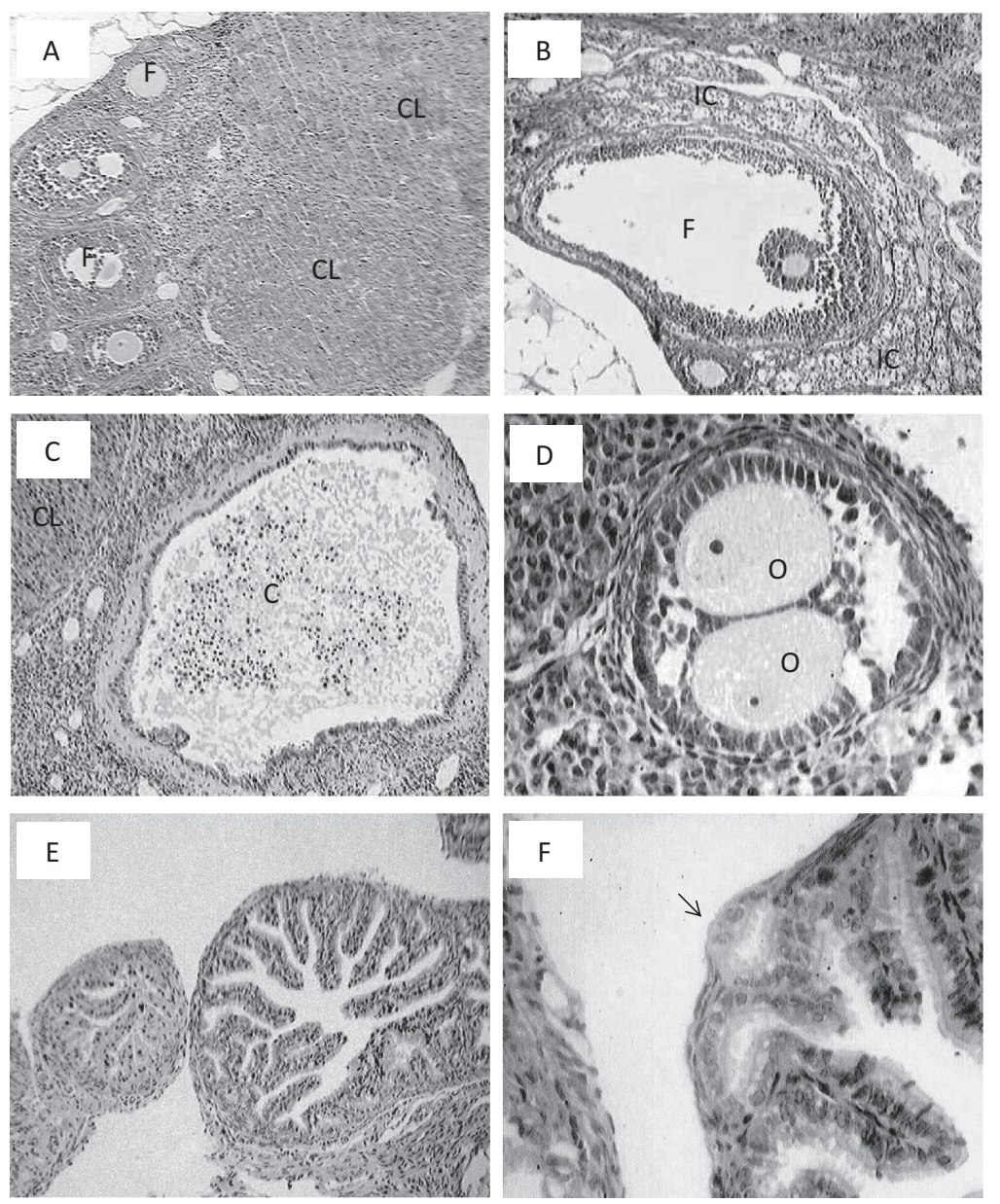

FIGURE 2. Representative microphotographs of ovary and oviduct from 4 mo-old mice treated with ISO. (A) Stroma of ovary that lacks eorpus luteum is filled with interstitial cells (IC). Note a big atrophic eyst like follicle (F) (5 d); H\&E, 100*. (B) A big cyst (C) with degenerating cells in the ovary; corpus luteum (CL) (5-d); H\&E, 100x. (C) A multiple oocyte follicle with two oocytes (O) (10d); H\&E, $400 *$. (D) Hyperplastic mucesal folds in the viduct have extended to the seresa (arrow) (10d); H\&E, 400*,

occurrence of hyperplasia, atypia, polyps, and cysts in the uterine tissue structure. These findings are comparable to changes observed in mice with neonatal exposure to potent environmental estrogens such as DES and bisphenolA and thes support the hypothesis that ISO bind to ER to induce estrogen-like effects in reproductive tissue (Adewale et al. 2009; Newbold et al. 2001; 2007). It is well documented that the unique biological response of a tissue to ISO involves three interrelated factors, including the type and level of $E R \alpha$ and $E R \beta$ expression, the nature of conformational change that occurs in the ER upon ligand binding, and the type and expression level of co-regulatory proteins (Riggs and Hartmann 2003). Both ER $\alpha$ and
ER $\beta$ are expressed in the female reproductive tissue during pregnancy (Couse et al. 1997; Jefferson et al. 2000; 2007b; Sar and Welsch 1999). In late gestation and early postnatal life, $E R \alpha$ is localized to the stromal and epithelial cells of the uterus and the interstitium of the ovary, while ER $\beta$ is limited to the ovarian granulosa cells with minimal expression in the uterus (Jefferson et al. 2000; 2007b; Sar and Welsch 1999; Yamashita et al. 1990). How this distribution of $E R \alpha$ and $E R \beta$ expression affects reproductive function is currently not well understood, but it is generally accepted that changes in ER expression might alter hormone production, nongenomic signaling, and the transcription of various genes including 

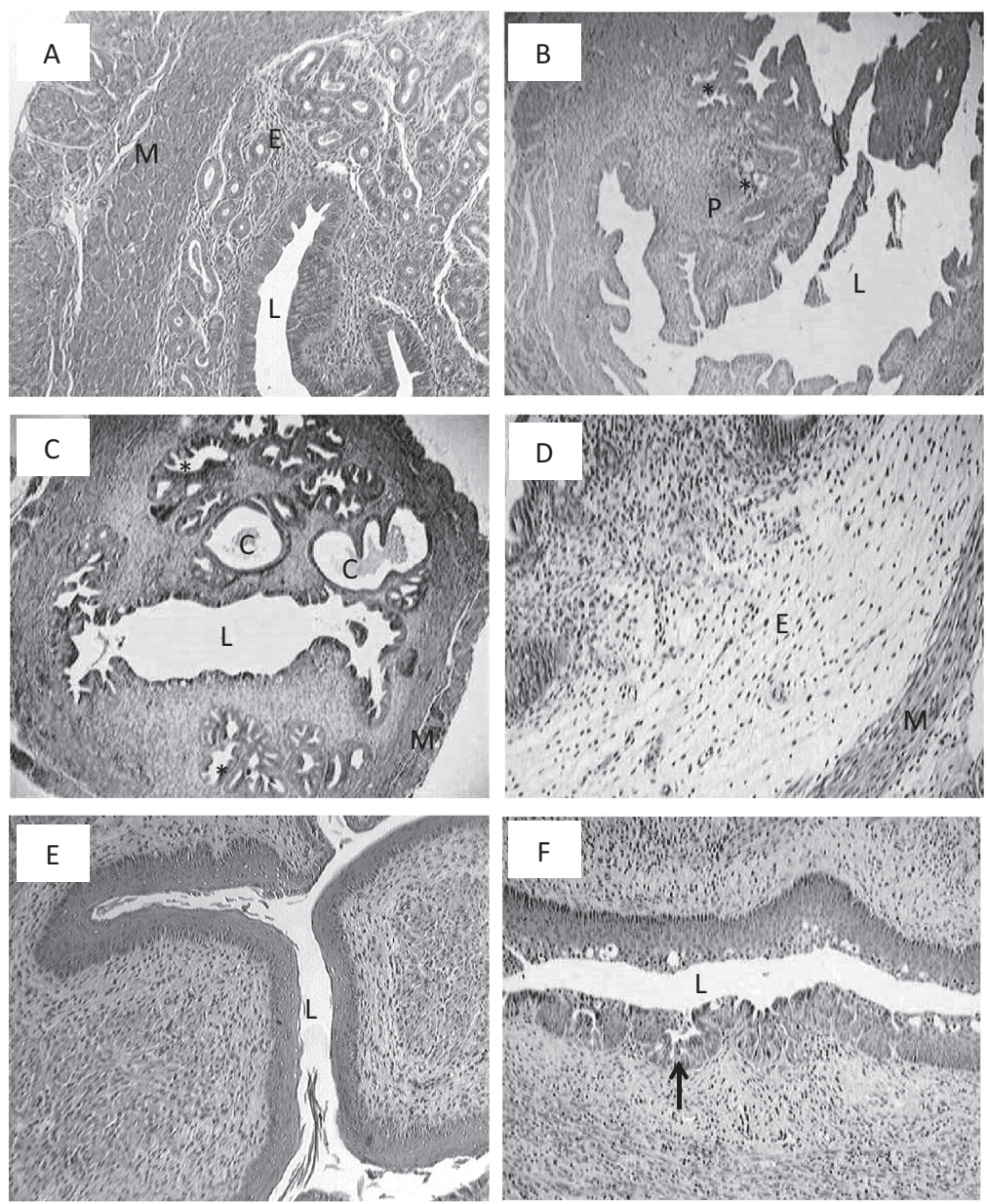

FIGURE 3. Representative microphotographs of uterus and cervix from 4 mo-old mice treated with ISO. (A) Uterine structure from a 10 dold corn oil treated mouse, uterine lumen (L), endometrium (E) myometrium (AM); H\& E. (B) Polyp (P) with hyperplastic glands (*); uterine lumen (L) (5-d); H\&E, 100x. (C) Cystic (C) and hyperplastic glands in the uterus (*); uterine lumen (L); myometrium (M) (5-d);

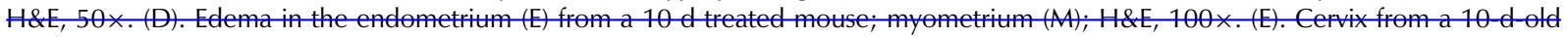
corn oil treated mouse; lumen (L) H\&E 100*. (F) Microglandular structures (arrow) in the cervix; lumen (L) (10d); H\&E, 100*2

steroid receptors, enzymes, and transcription factors. These changes have the potential to be inherited during cell division, resulting in permanent maintenance of the acquired phenotype (Day et al. 2002; Sato et al. 2009). In one study, rat pups whose lactating mothers were treated with ISO (100-200 mg/kg body weight/d) from PND 5 to 10 had higher expression of ER $\beta$ on PND 11 in the ovaries but lower expression in the uterus when compared to the control group (Liu et al. 2008). In a different study, continuous exposure to genistein, beginning prenatally to 21 or $97 \mathrm{~d}$ of life, resulted in lower mRNA expression of $E R \alpha$, $E R \beta$, complement component $3\left(C_{3}\right)$, clusterin
(Clu), insulin-like growth factor-1 (IGF-1), and IGF-1 receptor (IGF-1R) in the uterine tissue of juvenile mice (Moller et al. 2009). In utero exposure to genistein and daidzein, respectively, was also shown to induce hypermethylation of the transposable repetitive elements upstream of the transcription start site (Dolinoy et al. 2006) and to reduce expression of $E R \alpha$ in the brain of female mice (Yu et al. 2010), suggesting that ISO may exert profound effects on long-term programming of health. To better understand how ISO modulate reproductive health, further information on aberrant DNA methylation and gene expression including high-throughput analysis is required. 
Mouse studies investigating the effects of 405

environmental estrogens on programming of reproductive health have typically introduced the intervention in the first $5 \mathrm{~d}$ of life because this is the period when endogenous concentrations of sex steroid hormones are low (Cimafranca et al. 2010; Jefferson et al. 2002; 2005; 2006a; 2006b; 2007a; 2007b; 2009). However, mice suckle for the first $21 \mathrm{~d}$ of life, which is the time when human infants consume SPF, but reach sexual maturation shortly after the end of suckling. This makes it difficult to identify the most appropriate duration of exposure to mimic human infants fed SPF. A 10-d protocol was used in this study to more closely mimic the period when human infants are fed SPF while avoiding the time when suckling pups may start to consume maternal diet.

Overall, findings from this study indicate that the induction of numerous abnormalities in the ovaries and uteri of adult female mice is not significantly different between the 5- and the 10-d exposure to ISO. In agreement with this evidence, Dinsdale et al. (2011) recently showed that mice exposed to the same dose of ISO (7 mg/ $\mathrm{kg}$ body weight/d) used in this study for the first 10 or $21 \mathrm{~d}$ of life display comparable disruptions in ovarian folliculogenesis, uterine hyperplasia and atypia at 4 mo of age. Taken together, these studies suggest that the first $5 \mathrm{~d}$ of life represents a critical window of developing during which ISO can program reproductive health.

Jefferson et al. previously showed that CD-1 mice exposed to low doses of genistein $(0.5$ and $5 \mathrm{mg} / \mathrm{kg} / \mathrm{d})$ from PND 1 to 5 have an increased number of ovarian $\mathrm{CL}$, while those exposed to high doses of genistein $(50 \mathrm{mg} / \mathrm{kg} / \mathrm{d})$ have reduced number of ovarian $\mathrm{CL}$ at 4 mo of age (Jefferson et al. 2006b). In a separate study, C57BL mice exposed orally to a mixture of genistein $(50 \mathrm{mg} / \mathrm{kg} / \mathrm{d})$, soy protein formula and corn oil from PND1 to 5 had increased uterine weight and incidence of MOF in the ovaries on PND 5, but had normal fertility at 6 mo of age (Cimafranca et al. 2010). Based on these findings, Cimafranca et al. (2010) raised concern that genistein may exert adverse effects on reproductive development of human infants fed soy protein formula. However, the effects induced by genistein may be different from those induced by an ISO mixture. This study and another study from our laboratory showed that when genistein is administered in combination with daidzein for the first 5, 10, or $21 \mathrm{~d}$ of life, female mice have a reduced number of ovarian CL at 4 mo of age (Dinsdale et al. 2011). Fewer $C L$ indicate that ovulation is reduced. Whether these effects are due to daidzein per se or to its ability to attenuate the effect of genistein on the hypothalamicpituitary-gonadal axis has not been elucidated. One study showed that rats treated with $17 \beta$ estradiol or genistein for the first $5 \mathrm{~d}$ of life have a lower lordosis quotient at 2 mo of age, while those treated with daidzein have a higher lordosis quotient compared to the control group (Kouki et al. 2003). Lordosis quotient is a measure of sexual behaviour, and based on these findings it may be concluded that genistein and daidzein exert divergent effects on sexual differentiation of the brain and sexual behavior. Exposure to $17 \beta$-estradiol or genistein during neonatal development may increase responsiveness to estradiol in adulthood, while daidzein exposure may reduce responsiveness. Thus, genistein and daidzein may be inducing biological effects through different mechanisms.

Studies demonstrated that exposure to $7 \mathrm{mg}$ of ISO/ $\mathrm{kg}$ body weight for the first $5 \mathrm{~d}$ of life results in higher body weight at $28 \mathrm{wk}$ of age (Kaludjerovic and Ward 2010) but not at early stages of development (Cimafranca et al. 2010; Kaludjerovic and Ward 2009). However, this increase in body weight might be observed sooner if pups are exposed to higher doses of ISO in the first $5 \mathrm{~d}$ of life (Newbold et al. 2005), or if treatment is extended to first 10 or $21 \mathrm{~d}$ of life (Dinsdale et al. 2011). In this study, differences in body weight appeared on PND 6 and persisted to 4 mo of age when female mice were exposed to ISO from PND 1 to 10. Thus, while duration of ISO exposure affected body weight differently in this study, 5- and 10$\mathrm{d}$ exposure to ISO did not result in marked differences in the number of histological abnormalities in the ovaries or uteri, indicating that 
different tissues respond differently to ISO. The mechanism by which $10 \mathrm{~d}$ of exposure to ISO increases body weight but has no additional adverse effects on reproductive health remains to be elucidated.

This study is unique in that it compares the 5- and 10-d exposures to better characterize the critical window of development 510 during which ISO program reproductive health in CD-1 mice. It is generally accepted that no animal model exactly represents the human infant, but nonetheless might provide a useful basis for human studies (Dinsdale and Ward 2010; Klein et al. 2010; Reinwald and Weaver 2006). In conclusion, 5-d exposure represents a sensitive window of development during which exposure to ISO can alter structural development of ovaries and uteri in rodents

520 and may therefore be a factor in precocious human development. These findings raise concern that exposure to ISO during postnatal life may increase the risk of disrupting the structural development of reproductive organs. Findings from prospective studies of infants fed SPF, cow's milk formula, and breast milk, some of which are ongoing, are needed to address the paucity of data regarding the safety of ISO on structural and functional development of reproductive organs in adults.

\section{REFERENCES}

Adewale, H. B., Jefferson, W. N., Newbold, R. R., and Patisaul, H. B. 2009. Neonatal bisphenol-a exposure alters rat reproductive development and ovarian morphology without impairing activation of gonadotropinreleasing hormone neurons. Biol. Reprod. 81: 690-99.

Agostoni, C., Axelsson, I., Goulet, O., Koletzko, B., Michaelsen, K. F., Puntis, J., Rieu, D., Rigo, J., Shamir, R., Szajewska, H., and Turck, D. 2006. Soy protein infant formulae and follow-on formulae: A commentary by the ESPGHAN Committee on Nutrition.

Amleh, A., and Dean, J. 2002. Mouse genetics provides insight into folliculogenesis,

fertilization and early embryonic development. Human Reprod. Update 8: 395-403.

Arango, N. A., and Donahoe, P. K. 2008. Sex 550 differentiation in mouse and man and subsequent development of the female reproductive organs. StemBook. Cambridge, MA: Harvard Stem Cell Institute.

Barker, D. J. 2002. Fetal programming of coronary heart disease. Trends Endocrinol. Metab. 13: 364-68.

Bern, H. 1992. The fragile fetus. In Chemicallyinduced alterations in sexual and funcational development: The wildlife/human connection, eds. T. Colborn and C. Clement,. Princeton, NJ: Princeton Scientific ${ }_{2}$

Bernbaum, J. C., Umbach, D. M., Ragan, N. B., Ballard, J. L., Archer, J. I., Schmidt-Davis, H., and Rogan, W. J. 2008. Pilot studies of estrogen-related physical findings in infants. Environ. Health. Perspect. 116: 416-20.

Canadian Council on Animal Care. 1993. Guide to the care and use of experimental animals. Ottawa, ON: Canadian Council on Animal Care.

Cimafranca, M. A., Davila, J., Ekman, G. C., Andrews, R. N., Neese, S. L., Peretz, J., Woodling, K. A., Helferich, W. G., Sarkar, J., Flaws, J. A., Schantz, S. L., Doerge, D. R., and Cooke, P. S. 2010. Acute and chronic effects of oral genistein administration in neonatal mice. Biol. Reprod. 83: 114-21.

Couse, J. F., Lindzey, J., Grandien, K., Gustafsson, J. A., and Korach, K. S. 1997. Tissue distribution and quantitative analysis of estrogen receptor-alpha (ERalpha) and estrogen receptor-beta (ERbeta) messenger ribonucleic acid in the wild-type and ERalpha-knockout mouse. Endocrinol. 138: 4613-21.

Currie, A. J., Curtis, S., Strunk, T., Riley, K., Liyanage, K., Prescott, S., Doherty, D., Simmer, K., Richmond, P., and Burgner, D. 2011. Preterm infants have deficient monocyte and lymphocyte cytokine responses to group B streptococcus. Infect Immun. 79: 1588-96.

Day, J. K., Bauer, A. M., DesBordes, C., Zhuang, Y., Kim, B. E., Newton, L. G., Nehra, V., Forsee, K. M., MacDonald, 
R. S., Besch-Williford, C., Huang, T. H., and Lubahn, D. B. 2002. Genistein alters methylation patterns in mice. J. Nutr. 132: S2419-23.

Dinsdale, E. C., Chen, J., and Ward, W. E. 2011. Early life exposure to isoflavones adversely affects reproductive health in first but not second generation female CD1 mice. J. Nutr. 141: 1-7.

Dinsdale, E. C., and Ward, W. E. 2010. Early exposure to soy isoflavones and effects on reproductive health: A review of human and animal studies. Nutri. 2: 1156-87.

610 Dolinoy, D. C., Weidman, J. R., Waterland, R. A., and Jirtle, R. L. 2006. Maternal genistein alters coat color and protects Avy mouse offspring from obesity by modifying the fetal epigenome. Environ. Health

615 Perspect. 114: 567-72.

Gilchrist, J. M., Moore, M. B., Andres, A., Estroff, J. A., and Badger, T. M. 2010. Ultrasonographic patterns of reproductive organs in infants fed soy formula: Comparisons to infants fed breast milk and milk formula. J. Pediatr. 156: 215-20.

Gilchrist, J. M., Wiggins, P., Brackenbury, J., Worthen, A., Crook, T., Brodie, M., and Badger, T. M. 2004. Body composition among infants fed breast milk, milk-based formula or soy based formula: Preliminary data from the Beginnings Study. FASEB. J. 18: A1112 (abstr.).

Jefferson, W. N., Couse, J. F., Padilla-Banks, E., Korach, K. S., and Newbold, R. R. 2000. Expression of estrogen receptor $\{$ beta\} is developmentally regulated in reproductive tissues of male and female mice. Biol. Reprod. 62: 310-17.

635 Jefferson, W. N., Couse, J. F., Padilla-Banks, E., Korach, K. S., and Newbold, R. R. 2002. Neonatal exposure to genistein induces estrogen receptor (ER) \{alpha\} expression and multioocyte follicles in the maturing mouse ovary: Evidence for ER $\{$ beta $\}$ mediated and nonestrogenic actions. Biol. Reprod. 67: 1285-96.

Jefferson, W. N., Padilla-Banks, E., and Newbold, R. R. 2005. Adverse effects on
CD-1 mice following neonatal exposure to the phytoestrogen genistein at environmentally relevant doses. Biol. Reprod. 73: 798-806.

Jefferson, W. N., Newbold, R., Padilla-Banks, E., and Pepling, M. 2006a. Neonatal genistein treatment alters ovarian differentiation in the mouse: Inhibition of oocyte nest breakdown and increased oocyte survival. Biol. Reprod. 74: 161-68.

Jefferson, W. N., Padilla-Banks, E., and Newbold, R. R. 2006b. Studies of the effects of neonatal exposure to genistein on the developing female reproductive system. J. AOAC Int. 89: 1189-96.

Jefferson, W. N., Padilla-Banks, E., and Newbold, R. R. 2007a. Disruption of the female reproductive system by the phytoestrogen genistein. Reprod. Toxicol. 23: 308-16.

Jefferson, W. N., Padilla-Banks, E., and Newbold, R. R. 2007b. Disruption of the developing female reproductive system by phytoestrogens: Genistein as an example. Mol. Nutr. Food Res. 51: 832-44.

Jefferson, W. N., Doerge, D., Padilla-Banks, E., Woodling, K. A., Kissling, G. E., and Newbold, R. 2009. Oral exposure to genistin, the glycosylated form of genistein, during neonatal life adversely affects the female reproductive system. Environ. Health Perspect. 117: 1883-89.

Kaludjerovic, J., Franke, A. A., and Ward, W. E. 2017. Circulating isoflavonoid levels in CD1 mice: Effect of oral versus subcutaneous delivery and frequency of administration. J. Nutr. Biochem. [Epub ahead of print]. 680

Kaludjerovic, J., and Ward, W. E. 2008. Diethylstilbesterol has gender-specific effects on weight gain and bone development in mice. J. Toxicol. Environ. Health A. 71: 1032-42.

Kaludjerovic, J., and Ward, W. E. 2009. Neonatal exposure to daidzein, genistein, or the combination modulates bone development in female CD-1 mice. J. Nutr. 139: 467-73.

Kaludjerovic, J., and Ward, W. E. 2010. Neonatal administration of isoflavones 
attenuates deterioration of bone tissue in female but not male mice. J. Nutr. 140: 766-72.

Klein, M. A., Nahin, R. L., Messina, M. J., Rader, J. I., Thompson, L. U., Badger, T. M., Dwyer, J. T., Kim, Y. S., Pontzer, C. H., Starke-Reed, P. E., and Weaver, C. M. 2010. Guidance from an NIH workshop on designing, implementing, and reporting clinical studies of soy interventions. J. Nutr. 140: S1192-204.

Kouki, T., Kishitake, M., Okamoto, M., Oosuka, I., Takebe, M., and Yamanouchi, K. 2003. Effects of neonatal treatment with phytoestrogens, genistein and daidzein, on sex difference in female rat brain function: Estrous cycle and lordosis. Horm. Behav. 44: 140-45.

Lee, J. S., Ward, W. O., Knapp, G., Ren, H., Vallanat, B., Abbott, B., Ho, K., Karp,

715 S. J., and Corton, J. C. 2012. Transcriptional ontogeny of the developing liver. BMC Genomics 13: 33. [Epub ahead of print]

Liu, Z., Zhang, X., Li, L., Zhang, W., Cui, W., Song, Y., Wang, W., Jia, X., Li, N., and Yan, W. 2008. Effects of lactational exposure to soy isoflavones on reproductive system in neonatal female rats. Basic Clin. Pharmacol. Toxicol. 102: 317-24.

Magos, L. 2003. Neurotoxic character of thimerosal and the allometric extrapolation of adult clearance half-time to infants. J. Appl. Toxicol. 23: 263-69.

McCarver, G., Bhatia, J., Chambers, C., Clarke, R., Etzel, R., Foster, W., Hoyer, P., Leeder,

730 J. S., Peters, J. M., Rissman, E., Rybak, M., Sherman, C., Toppari, J., and Turner, K. 2011. NTP-CERHR expert panel report on the developmental toxicity of soy infant formula. Birth Defects Res. B Dev. Reprod. Toxicol. 92: 421-68.

Migliaccio, S., Newbold, R. R., Bullock, B. C., Jefferson, W. J., Sutton, F. G., Jr., McLachlan, J. A., Korach, K. S. 1996. Alterations of maternal estrogen levels during gestation affect the skeleton of female offspring. Endocrinology 137: 2118-25.

Moller, F. J., Zierau, O., Hertrampf, T., Bliedtner, A., Diel, P., and Vollmer, G. 2009.
Long-term effects of dietary isoflavones on uterine gene expression profiles. J. Steroid Biochem. Mol. Biol. 113: 296-303.

Newbold, R. R., Padilla-Banks, E., Bullock, B., and Jefferson, W. N. 2001. Uterine adenocarcinoma in mice treated neonatally with genistein. Cancer Res. 61: 4325-28.

Newbold, R. R., Padilla-Banks, E., Snyder, R. J., and Jefferson, W.N. 2005. Developmental exposure to estrogenic compounds and obesity. Birth Defects Res. A Clin. Mol. Teratol. 73: 478-80.

Newbold, R. R., Padilla-Banks, E., and Jefferson, W. N. 2006. Adverse effects of the model environmental estrogen diethylstilbestrol are transmitted to subsequent generations. Endocrinology 147: S11-17.

Newbold, R. R., Jefferson, W. N., and PadillaBanks, E.. 2007. Long-term adverse effects of neonatal exposure to bisphenol $\mathrm{A}$ on the murine female reproductive tract. Reprod. Toxicol. 24: 253-58.

Newbold, R. R., Jefferson, W. N., and PadillaBanks, E. 2009. Prenatal exposure to bisphenol a at environmentally relevant doses adversely affects the murine female reproductive tract later in life. Environ. Health Perspect. 117: 879-885.

Piekarz, A. V., and Ward, W. E. 2007. Effect of neonatal exposure to genistein on bone metabolism in mice at adulthood. Pediatr. Res. 61: 48-53.

Prescott, S. L., Taylor, A., King, B., Dunstan, J., Upham, J. W., Thornton, C. A., and Holt, P. G. 2003. Neonatal interleukin-12 capacity is associated with variations in allergenspecific immune responses in the neonatal and postnatal periods. Clin. Exp. Allergy. 33: 566-72.

Reinwald, S., and Weaver, C. M. 2006. Soy isoflavones and bone health: A doubleedged sword? J. Nat. Prod. 69: 450-59.

Riggs, B. L., and Hartmann, L. C. 2003. Selective estrogen-receptor modulatorsMechanisms of action and application to clinical practice. N. Engl. J. Med. 348: 618-29.

Sar, M., and Welsch, F. 1999. Differential expression of estrogen receptor-beta and 
estrogen receptor-alpha in the rat ovary. Endocrinology 140: 963-71.

Sato, K., Fukata, H., Kogo, Y., Ohgane, J., Shiota, K., and Mori, C. 2009. Neonatal exposure to diethylstilbestrol alters expression of DNA methyltransferases and methylation of genomic DNA in the mouse uterus. Endocr. J. 56: 131-39.

Strom, B. L., Schinnar, R., Ziegler, E. E., Barnhart, K. T., Sammel, M. D., Macones, G. A., Stallings, V. A., Drulis, J. M., Nelson, S. E., and Hanson, S. A. 2001. Exposure to soy-based formula in infancy and endocrinological and reproductive outcomes in young adulthood. J. Am. Med. Assoc. 286: 807-14.

Vieau, D. 2011. Perinatal nutritional programWorld J. Diabetes 2: 133-36.

Ward, W. E., Piekarz, A. V., and Fonseca, D. 2007. Bone mass, bone strength, and their relationship in developing CD-1 mice. Can. J. Physiol. Pharmacol. 85: 274-79.

Yamashita, S., Newbold, R. R., McLachlan, J. A., and Korach, K. S. 1990. The role of the estrogen receptor in uterine epithelial proliferation and cytodifferentiation in neonatal mice. Endocrinology 127: 2456-63.

Yu, C., Tai, F., Wu, R., Song, Z., Zhang, X., and An, X. 2010. Maternal exposure to daidzein alters behaviour and oestrogen receptor alpha expression in adult female offspring. Behav. Pharmacol. 21: 283-91.

Zung, A., Glaser, T., Kerem, Z., and Zadik, Z. 2008. Breast development in the first 2 years of life: An association with soy-based infant formulas. J. Pediatr. Gastroenterol. Nutr. 46: 191-95. 